\title{
ANÁLISE CRÍTICA DA DECISÃO DO SUPREMO TRIBUNAL FEDERAL NO JULGAMENTO DO RECURSO EXTRAORDINÁRIO 590415/SC: A QUESTÃO DA RENÚNCIA GENÉRICA A DIREITOS ORIUNDOS DA RELAÇÃO DE TRABALHO MEDIANTE ADESÃO A PLANO DE DEMISSÃO VOLUNTÁRIA
}

\author{
CRITICAL ANALYSIS OF THE BRAZILIAN SUPREME COURT DECISION IN THE LEADING CASE \\ 590415/SC: THE GENERAL WAIVER OF RIGHTS ARISING FROM THE EMPLOYMENT RELATIONSHIP \\ IN THE PLAN PREVIOUSLY APPROVED BY THE COLLECTIVE BARGAINING
}

\begin{abstract}
Resumo: Neste trabalho tem-se por escopo analisar a decisão proferida pelo Supremo Tribunal Federal no Recurso Extraordinário 590415/SC, que afirmou, com repercussão geral, em sentido contrário aos precedentes do Tribunal Superior do Trabalho, a tese de validade da renúncia genérica a direitos emergentes da relação de emprego mediante adesão do empregado a plano de demissão voluntária previamente aprovado por acordo coletivo de trabalho. Trata-se, com a identificação dos principais argumentos utilizados pelo Supremo Tribunal Federal na afirmação da tese, de problematizá-los à luz dos princípios e direitos fundamentais no trabalho, com especial ênfase para a questão da limitação da autonomia da vontade do empregado em razão da assimetria de poder entre os sujeitos da relação de emprego. Conclui-se que a decisão do Supremo Tribunal Federal constitui precedente flexibilizador desses princípios e direitos.
\end{abstract}

Palavras-chave: Demissão voluntária. Princípios e direitos fundamentais. Relação de trabalho. Renúncia. Transação.

\begin{abstract}
In this paper the scope is to analyze the decision of the Brazilian Supreme Court in the leading case 590415/SC, decision that, contrary to the decisions of the Brazilian Superior Labour Court, considers valid the general waiver of rights arising from the employment relationship in the plan previously approved by the collective bargaining. It deals with the identification of the main arguments used by the Supreme Court in the thesis statement, to discuss them according to the fundamental principles and rights at labour, with special emphasis on the limited autonomy of the employee because of the asymmetry of power between the subjects of the employment relationship. It is concluded that the decision of the Supreme Court set a flexibilizer precedent of these principles and rights.
\end{abstract}

Keywords: Voluntary resignation. Fundamental principles and rights. Labour relationship. Renunciation. Transaction.

\footnotetext{
* Doutor em Direito Público e em História Social pela Pontifícia Universidade Católica de São Paulo; Doutor em Direito do Trabalho e da Seguridade Social pela Universidad de Castilla-La Mancha; Professor do Programa de Pós-graduação em Direito (Mestrado) da Universidade do Oeste de Santa Catarina; Rua Getúlio Vargas, 2125, Flor da Serra, 89600-000, Joaçaba, Santa Catarina,Brasil;rodrigo.schwarz@trtsp.jus.br

** Doutor em Direito Público e Evolução Social pela Universidade Estácio de Sá; Professor do Programa de Pós-graduação em Direito (Mestrado) da Universidade do Oeste de Santa Catarina; Rua Getúlio Vargas, 2125, Flor da Serra, 89600-000, Joaçaba, Santa Catarina, Brasil; dr.rogerionery@gmail.com
} 


\section{Introdução}

O Direito do Trabalho, como disciplina da relação jurídica de emprego, tributário das grandes revoluções sociais do século XIX e do processo de "juridificação do bem-estar" dos dois primeiros terços do século XX (DEAN, 1997, p. 3), está profundamente ancorado, em termos históricos, filosófico-normativos e teórico-dogmáticos, no princípio da proteção. A originalidade do Direito do Trabalho reside, portanto, no seu objeto - a especial relação que disciplina, estruturalmente assimétrica em termos de poder, entre empregado e empregador - e no seu elemento teleológico fundamental - a proteção ao trabalho e ao trabalhador e, assim, à própria dignidade humana (XAVIER, 1993, p. 86) -, surgindo como consequência de uma reconhecida desigualdade, estrutural, e como sistema próprio de compensação dessa mesma desigualdade (RODRÍGUEZ, 1990, p. 25).

Seu fundamento e seu escopo, portanto, são claros, e, para salvaguardar a sua tessitura, desenvolveu-se uma luta por submeter os poderes do empregador e a própria autonomia da vontade do empregado a certos padrões mínimos, standards destinados à proteção do trabalho e do trabalhador, com foco na dignidade humana (CUEVA, 1972, p. 12). O Direito do Trabalho importa, nesse aspecto, uma tomada de posição sobre a realidade, adequando certos meios (estabelecendo limites ao poder diretivo do empregador e à autonomia da vontade do empregado) a determinados fins (proteção do trabalho e do trabalhador), fundando uma ordem econômica e social na qual as liberdades individuais se vinculam ao - e, consequentemente, limitam-se pelo - princípio da proteção do trabalho e do trabalhador (MEYER, 2006, p. 57): o escopo de proteção do trabalho e do trabalhador ensejou, assim, o desenvolvimento de um complexo sistema de garantias destinado a limitar, no âmbito dessa relação assimétrica, pautada pelos limites do poder diretivo do empregador e do direito de resistência do empregado, o poder diretivo do empregador e a autonomia da vontade do empregado (FREITAS JÚNIOR, 2014, p. 1681).

O Direito do Trabalho integra, segundo a Declaração Universal dos Direitos Humanos, ${ }^{1}$ o catálogo dos direitos humanos (art. 23). Além disso, é reconhecido como direito fundamental no âmbito do Pacto Internacional de Direitos Econômicos, Sociais e Culturais (arts. $6^{\circ}$ a $\left.8^{\circ}\right)^{2}$ e, no sistema interamericano de proteção dos direitos humanos, do "Protocolo de San Salvador" - Protocolo Adicional à Convenção Americana sobre Direitos Humanos em Matéria de Direitos Econômicos, Sociais e Culturais (arts. $6^{\circ}$ a $8^{\circ}$ ). ${ }^{3} \mathrm{Na}$ esteira da tendência iniciada com as Constituições do México de 1917 e da Alemanha de 1919, tem sido incorporado, nos países ocidentais, ao catálogo das garan-

\footnotetext{
1 A Declaração Universal dos Direitos Humanos foi adotada pela Organização das Nações Unidas (ONU) em 10 de dezembro de 1948 e firmada pelo Brasil na mesma data.

2 O Pidesc, adotado pela $21^{a}$ Assembleia-Geral das Nações Unidas (16 de dezembro de 1966), entrou em vigor em 03 de janeiro de 1976, em conformidade com o disposto no seu art. 27. O texto do Pacto, em vigência no Brasil, foi aprovado pelo Poder Legislativo brasileiro em dezembro de 1991 (Decreto Legislativo n. 226, de 12 de dezembro de 1991) e foi promulgado pelo Decreto n. 591, de 06 de julho de 1992, incorporando-se, então, à legislação nacional.

3 O Protocolo Adicional à Convenção Americana sobre Direitos Humanos em Matéria de Direitos Econômicos, Sociais e Culturais ("Protocolo de San Salvador"), adotado durante o $18^{\circ}$ Período Ordinário de Sessões da Assembleia-Geral da Organização dos Estados Americanos (17 de novembro de 1988), entrou em vigor em 16 de novembro de 1999, em conformidade com o disposto no seu art. 21. O texto do Protocolo, em vigência no Brasil, foi aprovado pelo Poder Legislativo brasileiro em abril de 1995 (Decreto Legislativo n. 56, de 19 de abril de 1995) e foi promulgado pelo Decreto n. ${ }^{\circ} 3.321$, de 30 de dezembro de 1999, incorporando-se, então, à legislação nacional.
} 
tias constitucionais - ou seja, dos direitos ditos fundamentais. Desde 1919, os International Labour Standards têm sido fixados pela Organização Internacional do Trabalho, instituída pelo Tratado de Versalhes, por meio de Convenções e Recomendações fundadas na convicção de que o trabalho não é uma mercadoria e da necessidade do estabelecimento de princípios e direitos fundamentais no trabalho verdadeiramente universais, para todos os trabalhadores. E as questões relacionadas ao Direito do Trabalho vêm sendo incorporadas às distintas convenções internacionais temáticas que têm sido adotadas em matéria de direitos humanos - a Convenção sobre os Direitos da Criança, a Convenção sobre os Direitos das Pessoas com Deficiência, a Convenção para a Eliminação de Todas as Formas de Discriminação contra a Mulher, etc.

No caso brasileiro, o Direito do Trabalho, incorporado à Constituição em 1934, é, com o seu viés protetivo do trabalho e do trabalhador, eloquentemente proclamado na Constituição de 1988, que eleva o primado do trabalho a princípio reitor da ordem econômica (art. 170) e da ordem social (art. 193). E, para além do complexo debate jurídico sobre as relações entre o direito internacional (direito dos direitos humanos) e o direito constitucional (direito dos direitos fundamentais) ${ }^{4}$ - monismo e dualismo -, a Constituição brasileira de 1988, seguindo a tradição do constitucionalismo social, tem, além de cláusulas que conferem um status especial aos tratados internacionais de direitos humanos, incorporado definitivamente os próprios direitos humanos - e com eles, o Direito do Trabalho - ao virtuoso catálogo das garantias constitucionais - ou seja, dos direitos ditos fundamentais.

Nesse sentido, o próprio Supremo Tribunal Federal já decidiu, por exemplo, a respeito dos tratados e convenções internacionais sobre o trabalho, que

[...] ainda quando não se queira comprometer o Tribunal com a tese da hierarquia constitucional dos tratados sobre direitos fundamentais [...], o mínimo a conferir-lhe é o valor de poderoso reforço à interpretação do texto constitucional que sirva melhor à sua efetividade: não é de presumir, em Constituição tão ciosa da proteção dos direitos fundamentais quanto a nossa, a ruptura com as convenções internacionais que se inspiram na mesma preocupação. (STF, ADI 1675/MC, DJ 19/09/2003).

No âmbito desses marcos, traçados pelo princípio da proteção, pro homine, com funções informativa, normativa e interpretativa, com o escopo de limitação do poder diretivo do empregador e da autonomia da vontade do empregado, desenvolve-se o princípio de irrenunciabilidade, que limita, no âmbito dos direitos e garantias do trabalho e do trabalhador, a validade da renúncia e da transação tanto no âmbito do projeto contratual traçado pelo empregador e pelo empregado quanto na execução dele (BAYLOS, 2014, p. 375) - a imperatividade dos preceitos de proteção e a sua eficácia horizontal limitam a autonomia da vontade das partes em prol dos direitos e garantias indisponíveis do trabalho e do trabalhador.

Essa irrenunciabilidade, que se depreende concretamente do princípio fundamental da Declaração Referente aos Fins e Objetivos da Organização Internacional do Trabalho (Declaração de Filadélfia), de que o trabalho não é uma mercadoria, é expressamente enunciada em várias Cons-

\footnotetext{
4 Para uma distinção básica entre as ideias de direitos humanos e de direitos fundamentais, ver Ferrajoli et al. (2001), Marshall e Bottomore (1998) e Martínez (1995).
} 
tituições latino-americanas, como a mexicana (arts. $5^{\circ}$ e 123), a boliviana (art. 48), a venezuelana (art. 89), a equatoriana (art. 31) e a costarriquenha (art. 74), e, no Brasil, está enunciada na própria Exposição de Motivos da Consolidação das Leis do Trabalho, que, adotando a prevalência da ordem institucional estatutária sobre a concepção contratualista no âmbito das relações de trabalho, funda-se na "precedência das 'normas' de tutela sobre os 'contratos'" (Item 28 da Exposição de Motivos).

No entanto, se, assim, é claro que o Direito do Trabalho está profundamente ancorado, em termos históricos, filosófico-normativos e teórico-dogmáticos, no princípio da proteção, e que este princípio se desvela, a partir da imperatividade dos preceitos de proteção, sobretudo, na irrenunciabilidade - ou seja, na limitação da autonomia da vontade do próprio empregado em prol dos seus direitos e garantias indisponíveis -, estando claros, portanto, o fundamento e o escopo dessa irrenunciabilidade, não estão suficientemente delineados os limites da irrenunciabilidade - o que é absolutamente irrenunciável, tido como o "mínimo de direito necessário" imperativo, e o que é, no âmbito da relação de emprego e do sistema de direitos e garantias do trabalho e do trabalhador, passível, de alguma forma e em algum grau, de renúncia ou transação, sobretudo pela via da negociação coletiva como mecanismo de flexibilização - esta mesma severamente limitada, também ela, em virtude do grau de indisponibilidade dos direitos trabalhistas tutelados por normas de interesse público.

Dessa forma, não são poucas as incongruências da jurisprudência a respeito da limitação da autonomia da vontade do empregado e, em consequência, da (in)validade da renúncia e da transação no que se refere a direitos trabalhistas. A Constituição, de certa forma, objetiva certas hipóteses de validade de renúncia ou transação - o faz, por exemplo, pelo reconhecimento dos acordos coletivos de trabalho; mas, tratando, embora, de reconhecer a força normativa dos acordos coletivos de trabalho (art. $7^{\circ}$, inc. XXVI), limita expressamente, no seu texto, o poder de disposição do sindicato em relação aos direitos individuais dos representados, estritamente, à fixação do salário e à fixação e à compensação da jornada (resguardados, em qualquer caso, certos limites mínimos, infensos à negociação coletiva, como a garantia de salário mínimo e a fixação da jornada ordinária no patamar máximo de quarenta e quatro horas semanais) -, sem que permita, pela via da negociação coletiva, a redução de outros direitos trabalhistas que contempla no seu texto. No entanto, a jurisprudência tem oscilado quanto à delimitação concreta da possibilidade de renúncia e de transação. $\bigcirc$ Tribunal Superior do Trabalho, assim, por exemplo, não tem reconhecido a validade da arbitragem para dirimir conflitos individuais do trabalho, dada a indisponibilidade dos direitos em questão; ${ }^{5}$ no entanto, tem admitido a renúncia genérica a direitos mediante transação extrajudicial, no caso das Comissões de Conciliação Prévia previstas na Lei n. 9.958/2000. ${ }^{6}$

\footnotetext{
5 Nesse sentido, por exemplo: "RECURSO DE REVISTA. ACORDO FIRMADO EM CÂMARA ARBITRAL - DISSÍDIO INDIVIDUAL DO TRABALHO - INCOMPATIBILIDADE. A aplicação do instituto da arbitragem no direito do trabalho esbarra em princípios constitucionais fundamentais, em face da peculiaridade da relação contratual envolvida no debate, frente aos direitos sociais indisponíveis inseridos no artigo $7^{\circ}$ da Carta Magna, e diante da impossibilidade de se compatibilizar subordinação e poder diretivo do empregador, ao qual está vinculado o empregado, com a livre opção em se submeter à arbitragem, o que implica na renúncia à jurisdição." (TST, 2a T., RR 39800-87.2009.5.15.0095, DEJT 29/10/2015).

6 Nesse sentido, por exemplo: "RECURSO DE REVISTA DA RECLAMADA ETE - ENGENHARIA DE TELECOMUNICAÇÕES E ELETRICIDADE LTDA. ACORDO FIRMADO PERANTE A COMISSÃO DE CONCILIAÇÃO PRÉVIA - CCP. AUSÊNCIA DE RESSALVAS. EFICÁCIA. [...] a dt. SBDI-1 do TST pacificou entendimento quanto ao caráter geral da quitação dada nas Comissões de Conciliação Prévia - CCPs. Para a SBDI-1, nos termos do parágrafo único do art. 625-E da CLT, ‘o
} 
No caso dos planos de demissão voluntária, a jurisprudência oscilou consideravelmente entre o reconhecimento e o não reconhecimento da validade da quitação geral do contrato individual do trabalho; no entanto, a jurisprudência mais contemporânea vinha inclinando-se em favor da tese do não reconhecimento. Assim, por exemplo, no âmbito dos Tribunais Regionais do Trabalho, evidenciam-se decisões mais antigas, favoráveis à quitação ampla (Proc. TRT-23-RO-01579.2003.004.23.00-9, DJMT 13/04/2005; Proc. TRT-3-RO-2394/01, DJMG 12/05/2001; Proc. TRT-7-014690029.2000.5.07.0002, DOJT 05/12/2003), e decisões mais recentes, a ela francamente desfavoráveis (Proc. TRT-2-RO-00010942120105020464, DeJT 29/08/2014; Proc. TRT-16-01860-2005-002-16-00-9, DeJT 04/05/2011; Proc. TRT-4-RO-0069500-05.2009.5.04.0002, DeJT 30/10/2012).

Mas no âmbito dos planos de demissão voluntária, o Tribunal Superior do Trabalho consolidou, mediante a Orientação Jurisprudencial n. 270 da sua SBDI-1, o entendimento de que "A transação extrajudicial que importa rescisão do contrato de trabalho ante a adesão do empregado a plano de demissão voluntária implica quitação exclusivamente das parcelas e valores constantes do recibo", descartando a possibilidade de renúncia genérica a direitos, ainda que o plano de demissão voluntária tenha esteio em acordo coletivo de trabalho, como decidido no julgamento do Incidente de Uniformização de Jurisprudência suscitado nos autos do ROAA 111500-48.2002.5.12.0000 (DJ 16/03/2007), derivado de ação anulatória de cláusula de acordo coletivo de trabalho proposta pelo Ministério Público do Trabalho, que concluiu pela invalidade de cláusula de acordo coletivo de trabalho que estabelece a quitação plena do contrato individual de trabalho em razão da adesão do empregado a plano de demissão incentivada.

Assim, se no próprio âmbito do Tribunal Superior do Trabalho a questão chegou a ser controvertida, podendo-se encontrar acórdãos mais antigos favoráveis à quitação ampla (RR 515.987/98.2, DJ 09/11/2001; RR 475.180-89.1998.5.12.5555, DJ 28/09/2001; RR 679586-20.2000.5.15.5555, DJ 17/08/2001) e acórdãos mais recentes a ela desfavoráveis (RR 222400-80.2003.5.02.0020, DeJT 24/02/2012; ED-RR 180500-21.2004.5.02.0461, DeJT 09/09/2011; RR 115400-28.2001.5.02.0008, DeJT 12/08/2011), o fato é que a jurisprudência trabalhista amadureceu, evoluindo no sentido de limitar a abrangência da quitação.

No entanto, o Supremo Tribunal Federal, no Recurso Extraordinário 590415/SC, interposto, contra decisão do Tribunal Superior do Trabalho, pelo Banco do Brasil S/A, sucessor do Banco do Estado de Santa Catarina S/A (BESC), afirmou, em sessão de 30 de abril de 2015 (DJE 29/05/2015), com repercussão geral, em sentido contrário aos precedentes do Tribunal Superior do Trabalho, a tese de validade da renúncia genérica a direitos emergentes da relação de emprego mediante adesão do empregado a plano de demissão voluntária previamente aprovado por acordo coletivo de trabalho:

\footnotetext{
termo de conciliação é título executivo extrajudicial e terá eficácia liberatória geral, exceto quanto às parcelas expressamente ressalvadas'. Na presente hipótese, o Tribunal Regional aplicou o entendimento de que o acordo efetuado perante a Comissão de Conciliação Prévia outorga quitação apenas em relação ao valor das verbas pagas, o que não constituiria óbice para a propositura de ação vindicando eventuais diferenças. Assim, constata-se que a decisão recorrida se encontra em desacordo com a atual jurisprudência dominante desta Corte Superior, motivo pelo qual se dá provimento ao presente recurso para extinguir o presente processo, julgando improcedentes os pedidos exordiais. Esclareça-se que, no presente processo, o TRT não registra ocorrência de vício de consentimento ou outro defeito grave do ato jurídico, atraindo a incidência da jurisprudência hoje dominante." (TST, $3^{a}$ T., ARR 1229-46.2011.5.04.0301, DEJT 20/11/2015).
} 
DIREITO DO TRABALHO. ACORDO COLETIVO. PLANO DE DISPENSA INCENTIVADA. VALIDADE E EFEITOS.

1. Plano de dispensa incentivada aprovado em acordo coletivo que contou com ampla participação dos empregados. Previsão de vantagens aos trabalhadores, bem como quitação de toda e qualquer parcela decorrente de relação de emprego. Faculdade do empregado de optar ou não pelo plano.

2. Validade da quitação ampla. Não incidência, na hipótese, do art. $477, \mathbb{S} 2^{\circ}$ da Consolidação das Leis do Trabalho, que restringe a eficácia liberatória da quitação aos valores e às parcelas discriminadas no termo de rescisão exclusivamente.

3. No âmbito do direito coletivo do trabalho não se verifica a mesma situação de assimetria de poder presente nas relações individuais de trabalho. Como consequência, a autonomia coletiva da vontade não se encontra sujeita aos mesmos limites que a autonomia individual.

4. A Constituição de 1988, em seu artigo $7^{\circ}$, XXVI, prestigiou a autonomia coletiva da vontade e a autocomposição dos conflitos trabalhistas, acompanhando a tendência mundial ao crescente reconhecimento dos mecanismos de negociação coletiva, retratada na Convenção n. 98/1949 e na Convenção n. 154/1981 da Organização Internacional do Trabalho. O reconhecimento dos acordos e convenções coletivas permite que os trabalhadores contribuam para a formulação das normas que regerão a sua própria vida.

5. Os planos de dispensa incentivada permitem reduzir as repercussões sociais das dispensas, assegurando àqueles que optam por seu desligamento da empresa condições econômicas mais vantajosas do que aquelas que decorreriam do mero desligamento por decisão do empregador. É importante, por isso, assegurar a credibilidade de tais planos, a fim de preservar a sua função protetiva e de não desestimular o seu uso.

7. Provimento do recurso extraordinário. Afirmação, em repercussão geral, da seguinte tese: "A transação extrajudicial que importa rescisão do contrato de trabalho, em razão de adesão voluntária do empregado a plano de dispensa incentivada, enseja quitação ampla e irrestrita de todas as parcelas objeto do contrato de emprego, caso essa condição tenha constado expressamente do acordo coletivo que aprovou o plano, bem como dos demais instrumentos celebrados com o empregado."

É esta, portanto, a decisão que passamos a examinar, identificando e problematizando os principais argumentos utilizados pelo Supremo Tribunal Federal na afirmação, com repercussão geral, da tese de que

A transação extrajudicial que importa rescisão do contrato de trabalho, em razão de adesão voluntária do empregado a plano de dispensa incentivada, enseja quitação ampla e irrestrita de todas as parcelas objeto do contrato de emprego, caso essa condição tenha constado expressamente do acordo coletivo que aprovou o plano, bem como dos demais instrumentos celebrados com o empregado. (BRASIL, 2012).

\section{Histórico processual}

Trata-se do Recurso Extraordinário 590415/SC, interposto, em 26 de junho de 2008, pelo Banco do Brasil S/A, sucessor do Banco do Estado de Santa Catarina S/A (BESC), contra acórdão do Tribunal Superior do Trabalho que, em Recurso de Revista, reformou decisão do Tribunal Regional do Trabalho da $12^{\text {a }}$ Região, que, por sua vez, havia confirmado a sentença trabalhista de primeira instância, que julgou improcedente a reclamação trabalhista ajuizada por ex-empregada do BESC após a respectiva adesão a plano de demissão incentivada. 
A ex-empregada postulava, mediante reclamação trabalhista, a condenação do ex-empregador ao pagamento de outras parcelas, derivadas do contrato individual de trabalho, não apontadas explicitamente na transação extrajudicial, ou seja, não consignadas, expressamente, no plano de demissão incentivada, tampouco nos instrumentos rescisórios por ela firmados. Na reclamação de origem, a reclamante reconhecia a sua adesão ao plano de demissão incentivada, bem como que havia firmado termo rescisório, outorgando quitação "ampla e irrestrita" de toda e qualquer importância a que poderia fazer jus, argumentando, embora, que, a par do teor explícito do termo rescisório, a quitação, dada a irrenunciabilidade dos direitos trabalhistas, somente poderia produzir efeitos jurídicos em relação às parcelas e aos valores efetivamente constantes do recibo por ela firmado, nos termos do art. 477, $\int 2^{\circ}$, da Consolidação das Leis do Trabalho, ${ }^{7}$ da Súmula n. 330 do Tribunal Superior do Trabalho $^{8}$ e da Orientação Jurisprudencial n. 270 da SBDI-1 do Tribunal Superior do Trabalho. ${ }^{9}$

Em sua contestação, o reclamado arguiu que o regulamento do plano de demissão incentivada previa, expressamente, que a adesão ao plano estaria condicionada à renúncia pelo empregado à estabilidade no emprego, prevista no regulamento da empresa, e à outorga de quitação "ampla e irrestrita de toda e qualquer verba oriunda do contrato de trabalho e eventualmente pendente", tratando-se de adesão voluntária, e que tal plano foi referendado por acordo coletivo de trabalho, aprovado em assembleia geral pelo Sindicato representativo dos bancários do Estado de Santa Catarina, razão pela qual não seria possível à reclamante questionar a validade da cláusula de quitação plena, também inserida no termo rescisório por ela firmado, destacando, por fim, que o termo rescisório foi homologado pela Delegacia Regional do Trabalho de Santa Catarina.

O entendimento de primeira instância, reafirmado pelo Tribunal Regional do Trabalho da $12^{a}$ Região em Recurso Ordinário, foi no sentido da validade da quitação total genérica (renúncia) por meio da transação extrajudicial, com a declaração de improcedência dos pedidos da reclamante. Asseverou-se, em primeira e segunda instâncias, então, em síntese, que o empregado que espontaneamente adere a programa de demissão incentivada, com cláusula expressa de quitação total do contrato aprovada por acordo coletivo de trabalho, recebe, por meio da transação extrajudicial, tudo o que lhe é devido, ficando impossibilitado de recorrer ao Judiciário para postular qualquer outra parcela relativa ao extinto contrato individual de trabalho, ainda que tais parcelas não estejam consignadas no recibo de quitação. Como fundamentos específicos da decisão de primeiro grau, constam, especialmente:

\footnotetext{
7 "O instrumento de rescisão ou recibo de quitação, qualquer que seja a causa ou forma de dissolução do contrato, deve ter especificada a natureza de cada parcela paga ao empregado e discriminado o seu valor, sendo válida a quitação, apenas, relativamente às mesmas parcelas."

8 "QUITAÇÃO. VALIDADE. A quitação passada pelo empregado, com assistência de entidade sindical de sua categoria, ao empregador, com observância dos requisitos exigidos nos parágrafos do art. 477 da CLT, tem eficácia liberatória em relação às parcelas expressamente consignadas no recibo, salvo se oposta ressalva expressa e especificada ao valor dado à parcela ou parcelas impugnadas. I - A quitação não abrange parcelas não consignadas no recibo de quitação e, consequentemente, seus reflexos em outras parcelas, ainda que estas constem desse recibo. II - Quanto a direitos que deveriam ter sido satisfeitos durante a vigência do contrato de trabalho, a quitação é válida em relação ao período expressamente consignado no recibo de quitação."

9 "A transação extrajudicial que importa rescisão do contrato de trabalho ante a adesão do empregado a plano de demissão voluntária implica quitação exclusivamente das parcelas e valores constantes do recibo."
} 
a) os instrumentos firmados pela reclamante, desde o momento da manifestação de interesse em aderir ao plano de demissão incentivada até a resilição contratual efetiva, previam expressamente que a rescisão ensejaria a quitação plena de toda e qualquer verba trabalhista;

b) o plano de demissão incentivada baseou-se em acordo coletivo de trabalho celebrado após ampla discussão em assembleia sindical, tendo havido pressão dos próprios empregados do BESC pela formalização do plano, mesmo contra a orientação da entidade de classe;

c) o valor do montante pago à reclamante em virtude da sua adesão superou o valor correspondente às verbas rescisórias a ela devidas: a reclamante recebeu o valor total bruto de $\mathrm{R}$ \$ 134.811,72, sendo R \$ 129.329,01 a título indenizatório e o restante pelas verbas rescisórias de praxe;

d) é válida a quitação plena (genérica), porque a reclamante tinha plena ciência das consequências desta.

No entanto, o Tribunal Superior do Trabalho, já havendo firmado, no âmbito dos planos de demissão voluntária, por meio da Orientação Jurisprudencial n. 270 da sua SBDI-1, o entendimento de que "A transação extrajudicial que importa rescisão do contrato de trabalho ante a adesão do empregado a plano de demissão voluntária implica quitação exclusivamente das parcelas e valores constantes do recibo", descartando a possibilidade de renúncia genérica a direitos, ainda que o plano de demissão voluntária tenha esteio em acordo coletivo de trabalho, como decidido no julgamento do Incidente de Uniformização de Jurisprudência suscitado nos autos do ROAA 11150048.2002.5.12.0000 (DJ 16/03/2007), que concluiu pela invalidade de cláusula de acordo coletivo de trabalho que estabelece a quitação plena do contrato individual de trabalho em razão da adesão do empregado a plano de demissão incentivada, reformou, em Recurso de Revista, a decisão do Tribunal Regional do Trabalho da $12^{a}$ Região, determinando o retorno dos autos à primeira instância para 0 julgamento dos pedidos formulados pela ex-empregada em face do ex-empregador, correspondentes àquelas parcelas não discriminadas nos instrumentos rescisórios por ela firmados.

A tese assentada no Tribunal Superior do Trabalho era, então, a de que "A transação extrajudicial que importa rescisão do contrato de trabalho ante a adesão do empregado a plano de demissão voluntária implica quitação exclusivamente das parcelas e valores constantes do recibo." Tal tese, ancorada, também, no entendimento jurisprudencial consolidado no âmbito do Tribunal Superior do Trabalho, segundo a sua Súmula n. 330 -

A quitação passada pelo empregado, com assistência de entidade sindical de sua categoria, ao empregador, com observância dos requisitos exigidos nos parágrafos do art. 477 da CLT, tem eficácia liberatória em relação às parcelas expressamente consignadas no recibo, salvo se oposta ressalva expressa e especificada ao valor dado à parcela ou parcelas impugnadas. I - A quitação não abrange parcelas não consignadas no recibo de quitação e, consequentemente, seus reflexos em outras parcelas, ainda que estas constem desse recibo. II - Quanto a direitos que deve- 
riam ter sido satisfeitos durante a vigência do contrato de trabalho, a quitação é válida em relação ao período expressamente consignado no recibo de quitação.

-, fora reforçada em relação aos precedentes do BESC por meio do julgamento do Incidente de Uniformização de Jurisprudência suscitado nos autos do ROAA 111500-48.2002.5.12.0000 (DJ 16/03/2007), derivado de ação anulatória de cláusula de acordo coletivo de trabalho proposta pelo Ministério Público do Trabalho, já que, no caso dos planos de demissão incentivada do BESC, a estabilidade dos empregados, prevista em regulamento da empresa, vedava a resilição dos contratos individuais de trabalho, o que levou à celebração de acordo coletivo de trabalho, pelo qual, por intermédio do Sindicato representativo da categoria profissional, firmou-se a possibilidade de renúncia ao direito à estabilidade, juntamente com a quitação plena, geral e irrestrita do contrato individual de trabalho, como contrapartida ao recebimento da indenização prevista no plano de demissão incentivada.

No caso, como fundamentos específicos da decisão de grau especial, constam, especialmente:

a) a quitação somente libera o empregador das parcelas estritamente lançadas no termo rescisório, nos termos do art. 477, $\$ 2^{\circ}$, da Consolidação das Leis do Trabalho;

b) todos os termos rescisórios de contratos individuais de trabalho provenientes do BESC mencionavam, genericamente, as mesmas parcelas como quitadas, sempre nos mesmos percentuais indenizatórios, o que demonstraria que não foram apuradas as verbas rescisórias efetivamente devidas em cada caso, a cada ex-empregado, havendo sido elaborados termos rescisórios genéricos, pro forma, fundados em percentuais hipotéticos;

c) a transação pressupõe concessões recíprocas a respeito de res dubia, elemento inexistente no caso;

d) a transação interpreta-se restritivamente;

e) os direitos trabalhistas são indisponíveis e, portanto, irrenunciáveis;

f) deve-se tratar "com naturais reservas" a transação extrajudicial no plano do Direito do Trabalho, "máxime se firmada na vigência do contrato de emprego".

No Recurso Extraordinário, interposto após a oposição de embargos de declaração para fins de prequestionamento, os argumentos do Banco do Brasil S/A centraram-se na afirmação de que a rescisão do contrato individual de trabalho decorreu da adesão da reclamante a plano de demissão incentivada e de que as cláusulas do correspondente termo rescisório foram aprovadas mediante acordo coletivo de trabalho, de forma que a decisão do Tribunal Superior do Trabalho violaria o ato jurídico perfeito (art. $5^{\circ}$, XXXVI, da Constituição) e o direito ao reconhecimento dos acordos coletivos de trabalho (art. $7^{\circ}$, XXVI, da Constituição).

A questão de mérito colocada ao Supremo Tribunal Federal, portanto, poderia ser assim formulada: "[...] a transação extrajudicial que importa rescisão do contrato de trabalho, em razão de adesão voluntária do empregado a plano de demissão incentivada, pode ensejar quitação ampla 
e irrestrita de todas as parcelas objeto do contrato de emprego, caso essa condição tenha constado expressamente do acordo coletivo que aprovou o plano? Ou, em outros termos: $\bigcirc$ acórdão do TST que recusa validade à transação com tal amplitude enseja violação ao ato jurídico perfeito (art. $5^{\circ}$, XXXVI, CF) ou ao direito dos trabalhadores ao reconhecimento dos acordos coletivos (art. $7^{\circ}$, XXVI, CF)?" (Relatório do Min. Relator).

O Recurso Extraordinário foi admitido e distribuído ao Ministro Menezes Direito, e teve, em sessão de 06 de março de 2009 (DJE 07/08/2009), a sua repercussão geral reconhecida, nos seguintes termos: "Direito do trabalho. Plano de Demissão Voluntária. Adesão. Efeitos. Matéria infraconstitucional. Existência de repercussão geral." O Recurso seria, ainda, sucessivamente redistribuído aos Ministros Joaquim Barbosa e Roberto Barroso.

Ao se manifestar nos autos, a Procuradoria Geral da República proferiu parecer pelo não provimento do Recurso Extraordinário, com base em argumentos similares àqueles utilizados pelo Tribunal Superior do Trabalho, em que se funda o acórdão recorrido.

Por fim, em sessão de 30 de abril de 2015 (DJE 29/05/2015), o Supremo Tribunal Federal, julgando o Recurso Extraordinário 590415/SC, afirmou, com repercussão geral, por unanimidade (ressalvadas a ausência dos Ministros Celso de Mello e Dias Toffoli e a abstenção, por impedimento, da Ministra Rosa Weber, já que esta já havia, na condição de Ministra do Tribunal Superior do Trabalho, participado de julgamentos a respeito da matéria, corroborando a tese em que se funda o acórdão recorrido - por exemplo, no RR 742500-28.2009.5.12.0014, DEJT 30/09/2011), a tese de validade da renúncia genérica a direitos emergentes da relação de emprego mediante adesão do empregado a plano de demissão voluntária previamente aprovado por acordo coletivo de trabalho.

\section{Os fundamentos da decisão do Supremo Tribunal Federal}

No voto condutor, o Ministro Roberto Barroso tratou de enfrentar a questão referente ao alcance da autonomia da vontade no âmbito do Direito do Trabalho. Nesse sentido, reconhece que o Direito do Trabalho se rege, fundamentalmente, pelo princípio da proteção, e que essa lógica protetiva está presente na Constituição, que "[...] consagrou um grande número de dispositivos à garantia de direitos trabalhistas no âmbito das relações individuais." Essa mesma lógica, continua, “[... encontra-se presente no art. 477, $\$ 2^{\circ}$, da CLT e na Súmula 330 do TST, quando se determina que a quitação tem eficácia liberatória exclusivamente quanto às parcelas consignadas no recibo, independentemente de ter sido concedida em termos mais amplos."

No entanto, ressalva que, se por um lado, "Não se espera que o empregado, no momento da rescisão de seu contrato, tenha condições de avaliar se as parcelas e valores indicados no termo de rescisão correspondem efetivamente a todas as verbas a que faria jus", e "a condição de subordinação, a desinformação ou a necessidade podem levá-lo a agir em prejuízo próprio", motivo pelo qual "a quitação, no âmbito das relações individuais, produz efeitos limitados", por outro, "tal assimetria entre empregador e empregados não se coloca - ao menos não com a mesma força - nas relações coletivas." 
Por isso, prossegue o Ministro Roberto Barroso, porque "[...] a Constituição prestigiou a negociação coletiva, bem como a autocomposição dos conflitos trabalhistas, através dos sindicatos", e de acordo com as Convenções nº 94 e 154 da Organização Internacional do Trabalho, a rigorosa limitação da autonomia da vontade, que é a tônica do direito individual do trabalho e da legislação infraconstitucional anterior à Constituição de 1988, não prospera no que diz respeito ao direito coletivo do trabalho ou às normas constitucionais atualmente em vigor - a Constituição de 1988, prossegue, "Especificamente no que respeita ao direito coletivo do trabalho [...], prestigiou a autonomia coletiva da vontade como mecanismo pelo qual o trabalhador contribuirá para a formulação das normas que regerão a sua própria vida, inclusive no trabalho."

Nesse contexto, o Sindicato, contraposto ao empregador, teria [...] considerável poder de barganha, assegurado, exemplificativamente, pelas prerrogativas de atuação sindical, pelo direito de mobilização, pelo poder social de pressão e de greve, neutralizando-se a assimetria de poder presente nas relações individuais de trabalho." Por consequência, " [...] a autonomia coletiva da vontade não se encontra sujeita aos mesmos limites que a autonomia individual", destacando-se, como princípio do direito coletivo do trabalho, "[...] a equivalência dos contratantes coletivos, que impõe o tratamento semelhante a ambos os sujeitos coletivos - empregador e categoria de empregados."

Nessa linha, conclui o Ministro Roberto Barroso,

[...] não deve ser vista com bons olhos a sistemática invalidação dos acordos coletivos de trabalho com base em uma lógica de limitação da autonomia da vontade exclusivamente aplicável às relações individuais de trabalho. Tal ingerência viola os diversos dispositivos constitucionais que prestigiam as negociações coletivas como instrumento de solução de conflitos coletivos, além de recusar aos empregados a possibilidade de participarem da formulação de normas que regulam as suas próprias vidas. Trata-se de postura que, de certa forma, compromete o direito de serem tratados como cidadãos livres e iguais.

Por outro lado, de uma forma mais pragmática, afirma o Ministro Roberto Barroso que "[...] as PDIs possibilitam [...] reduzir a repercussão social das dispensas, assegurando àqueles que optam por seu desligamento da empresa condições econômicas mais vantajosas do que aquelas que decorreriam da mera dispensa por decisão do empregador. As demissões coletivas, ao contrário, geram greves, comoção, desemprego e oneração do seguro social."

Nesses termos, conclui o Relator,

[...] não há qualquer argumento que justifique o não reconhecimento da quitação plena outorgada pela reclamante ou que enseje a invalidade do acordo coletivo que a autorizou. Ao fazê-lo, a decisão recorrida incorreu em violação ao art. $7^{\circ}$, XXVI, da Constituição, uma vez que negou reconhecimento ao acordo coletivo com base em fundamentos ilegítimos, sendo de se destacar que o respeito a tais acordos preserva o interesse da classe trabalhadora de dispor desse instrumento essencial à adequação das normas trabalhistas aos momentos de crise e à minimização dos danos ensejados por dispensas em massa.

Assim, assenta-se, a partir do voto condutor, com o julgamento do Recurso Extraordinário 590415/SC, a tese, com repercussão geral, de que "A transação extrajudicial que importa rescisão do contrato de trabalho, em razão de adesão voluntária do empregado a plano de dispensa incentivada, 
enseja quitação ampla e irrestrita de todas as parcelas objeto do contrato de emprego, caso essa condição tenha constado expressamente do acordo coletivo que aprovou o plano, bem como dos demais instrumentos celebrados com o empregado."

\section{Análise crítica dos fundamentos da decisão do Supremo Tribunal Federal}

A tese esposada pelo Supremo Tribunal Federal, ainda que pautada em standards teoréticos de proteção logicamente razoáveis, flexibilizando um dos principais - se não o principal - cânones do Direito do Trabalho (o princípio da irrenunciabilidade), vai ao encontro, nos seus fundamentos, de um movimento de flexibilização do Direito do Trabalho, de prevalência do negociado coletivamente sobre o legislado, fortemente refutado pela sociedade brasileira há 14 anos, que se materializou no Projeto de Lei n. 5.483/2001, que, reconhecendo a ampla autonomia coletiva no Direito do Trabalho, pretendia tornar válida a negociação coletiva tout court, justamente a partir da argumentação de que, no âmbito do direito coletivo do trabalho, a assimetria inerente à relação de emprego é neutralizada. Embora arquivado o Projeto de Lei n. 5.483/2001, novo projeto foi recentemente inserido, de forma enviesada (sem pertinência temática com a matéria de fundo tratada na Medida Provisória), por meio de emenda, no texto da Medida Provisória n. 680, que trata do Programa de Proteção ao Emprego, em tramitação no Congresso Nacional, dispondo, na matéria, que:

Art. 11. O art. 611 da Consolidação das Leis do Trabalho - CLT, aprovada pelo Decreto-lei $\mathrm{n}^{\circ} 5.452$, de $1^{\circ}$ de maio de 1943 , passa a vigorar acrescido dos seguintes parágrafos:

"Art. 611

$\int 3^{\circ}$ As condições de trabalho ajustadas mediante convenção ou acordo coletivo de trabalho prevalecem sobre o disposto em lei, desde que não contrariem ou inviabilizem direitos previstos na Constituição Federal, nas convenções da Organização Internacional do Trabalho - OIT, ratificadas pelo Brasil, e as normas de higiene, saúde e segurança do trabalho.

$\int 4^{\circ}$ Para o efeito previsto no caput deste artigo, deve ser ampla a divulgação da assembleia geral que autorize a celebração de convenção ou acordo coletivo, garantida a participação e o voto de todos os interessados.

Art. 12. A prevalência das convenções e acordos coletivos trabalhistas sobre as disposições legais, consoante a redação dada pelo art. 11 ao art. 611 da Consolidação das Leis do Trabalho (CLT), aprovada pelo Decreto-lei no 5.452 , de $1^{\circ}$ de maio de 1943, aplica-se somente aos instrumentos negociais coletivos posteriores à publicação desta Lei e não prejudica a execução daqueles em andamento e os direitos adquiridos em razão da lei, de contrato ou de convenções e acordos coletivos anteriores."

Assim, na prática, o Supremo Tribunal Federal ocupou-se de consagrar, em termos de flexibilização do Direito do Trabalho, ainda que com argumentos pautados em standards teoréticos de proteção logicamente razoáveis, o escopo do mainstream dos movimentos conservadores que (ainda) não tiveram fôlego para fazê-lo pela via do Poder Legislativo, consagrando, em repercussão geral, um viés flexibilizador do princípio da irrenunciabilidade.

Tal viés está claramente estampado no voto condutor do Ministro Roberto Barroso, que, após as amplas considerações jurídicas a respeito da matéria, reproduz, como argumento final e 
decisivo, a autoridade da falácia amplamente replicada pelos movimentos de flexibilização: é do interesse da "classe trabalhadora" dispor desse instrumento essencial (os acordos coletivos de trabalho) à "adequação" das normas trabalhistas aos momentos de crise e à minimização dos danos ensejados por dispensas em massa. Caberia perguntar, obviamente, no caso do BESC, em análise, de que crise estaríamos falando, quando estamos, de fato, diante da federalização de instituição financeira pública estadual, sucedida pelo Banco do Brasil S/A, de ilibada idoneidade econômica, e de que "dispensas em massa" estaríamos falando, quando esses empregados têm garantida, por regulamento da própria empresa, a estabilidade no emprego.

Como já se expôs - e o reconhece, em termos, o Supremo Tribunal Federal -, é claro que o Direito do Trabalho está profundamente ancorado, em termos históricos, filosófico-normativos e teórico-dogmáticos, no princípio da proteção, e que este princípio se desvela, a partir da imperatividade dos preceitos de proteção, sobretudo, na irrenunciabilidade - ou seja, na limitação da autonomia da vontade do próprio empregado em prol dos seus direitos e garantias indisponíveis -, em razão da assimetria de poder entre os sujeitos da relação de emprego no âmbito do direito fundamental ao trabalho, estando claros, portanto, o fundamento e o escopo dessa irrenunciabilidade.

Um equívoco grave, contudo, reside em minimizar os efeitos dessa assimetria no âmbito da negociação coletiva, ou de relacionar a negociação coletiva, necessariamente, a um processo democrático e virtuoso de autocomposição entre atores igualmente empoderados, em que o procedimento, de per si, legitima a "justa solução" de chegada, inclusive contra procedimentos instaurados pelo Ministério Público do Trabalho e contra sucessivas decisões do Tribunal Superior do Trabalho, pautadas na realidade observada, ou, ainda, de superestimar a negociação coletiva, inclusive a partir de preceitos emanados da Organização Internacional de Trabalho, descontextualizando-a da realidade nacional em termos de liberdade sindical e de negociação coletiva, censurada, em seus standards, pela própria Organização Internacional de Trabalho - vale dizer, preconizando-se a aplicação de standards da Organização Internacional de Trabalho, como fins em si mesmos, quando esses standards, que são meramente instrumentais no sistema de princípios e direitos fundamentais no trabalho da Organização Internacional do Trabalho, não têm, no País, segundo a própria Organização Internacional do Trabalho - e, em especial, segundo o Comitê de Liberdade Sindical da Organização Internacional do Trabalho -, minimamente respeitados os supostos fundamentais de sua aplicação a liberdade sindical, em especial (ressalvando-se que, das oito Convenções internacionais reputadas fundamentais, segundo a Declaração da Organização Internacional do Trabalho, de 1998, sobre os Princípios e Direitos Fundamentais no Trabalho, o Brasil não ratificou, precisamente, aquela que se considera a primeira - e a mais fundamental - de todas, dada a sua natureza instrumental, como viabilizadora que é das demais, a Convenção n. 87, acerca da liberdade sindical e da proteção ao direito de sindicalização).

Não deixa de causar perplexidade, assim, no voto do Ministro Roberto Barroso, a crítica à origem autoritária, em Vargas, da legislação trabalhista infraconstitucional anterior à Constituição de 1988, com rigorosa limitação da autonomia da vontade, que se soma à fé, no seu voto condutor, no Sindicato e na negociação coletiva, cujo estatuto remonta exatamente à mesma "origem auto- 
ritária", em Vargas, sendo o sistema sindical brasileiro censurado, na atualidade, pela Organização Internacional do Trabalho em razão da estrutural violação da liberdade sindical que supõe.

Outra questão, talvez mais grave, é a de desconectar os princípios básicos que informam os institutos da transação e da renúncia com a teleologia da ordem jurídica trabalhista e, sobretudo, com o princípio fundamental de garantia de acesso do ex-empregado à jurisdição trabalhista (art. $5^{\circ}, \mathrm{XXXV}$, da Constituição), principalmente quando isso é feito a pretexto da necessidade de prevenção e pacificação de conflitos, argumenta-se, por exemplo, por um lado, pela simetria das partes envolvidas no conflito coletivo, porque o Sindicato tem a prerrogativa de desencadear a greve, mas se aponta, por outro lado, a resolução extrajudicial do conflito, inviabilizando-se aos trabalhadores implicados a possibilidade de acesso ao Poder Judiciário, como mecanismo, paradoxalmente, negador do conflito e impeditivo da indesejável greve e da suposta instabilidade social que esta, em tese, suporia (desconhecendo-se a própria máxima da Organização Internacional do Trabalho, inserida na sua Constituição, de que não há paz sem justiça social).

É de se lembrar, no caso paradigma, que não se está diante de uma renúncia firmada em sede de negociação coletiva - esta mesma, como já afirmamos, severamente limitada em virtude do grau de indisponibilidade dos direitos trabalhistas tutelados por normas de interesse público, e que somente pode, se utilizada regressivamente, in peius, para o trabalhador, ocorrer segundo o que autoriza expressamente a Constituição, nos campos da fixação do salário e da fixação e compensação da jornada (resguardados, em qualquer caso, certos limites mínimos, infensos à negociação coletiva, como a garantia de salário mínimo e a fixação da jornada ordinária no patamar máximo de quarenta e quatro horas semanais) -, mas de uma autorização genérica, com fulcro em negociação coletiva, para a renúncia individual, o que continua a atrair, quanto à virtual renúncia de cada empregado individualmente considerado, a problemática, quanto ao momento e ao escopo da renúncia, da limitação da autonomia da vontade do empregado em razão da assimetria de poder entre os sujeitos da relação de emprego.

A sentença de primeira instância, no caso, já reconhecia que houve pressão dos próprios empregados do BESC pela formalização do plano, "mesmo contra a orientação da entidade de classe", o que coloca em cheque a assimetria na negociação coletiva, que, no fundo, no caso paradigma, nada mais fez do que veicular um feixe de pretensões individuais, avidamente direcionadas à renúncia individual, em cada caso concreto, de direitos indisponíveis dos trabalhadores em questão.

Por fim, e tão grave quanto os anteriores, não pode deixar de ser um equívoco ignorar os anos de desenvolvimento e amadurecimento da jurisprudência trabalhista e as experiências empíricas, concretas, de quem viveu o quotidiano de tais negociações coletivas, deixando, em prol de um suposto - e teorético - caráter benéfico dos planos de demissão incentivada, destinados, no setor bancário, sobretudo ao expurgo de passivos trabalhistas em momentos de federalização para fins de privatização da instituição financeira estadual, de ouvir a eloquente fundamentação dos acórdãos do Tribunal Superior do Trabalho quanto à potencial invalidade dos instrumentos coletivos em questão, suscitada pelo Ministério Público do Trabalho e, por isso mesmo, reafirmada pela Procuradoria Geral da República. 
"Modernizar" o Direito do Trabalho, flexibilizando-o, sob a argumentação de efetivá-lo, reduzindo custos trabalhistas por quitações genéricas dadas em sede de transações extrajudiciais, ainda que respaldadas por acordo coletivo de trabalho, acordo este celebrado em razão da vontade individual de cada trabalhador isoladamente considerado, "contra a orientação da entidade de classe", não deixa de ser, com a flexibilização de um dos principais - se não o principal - cânones do Direito do Trabalho (o princípio da irrenunciabilidade), uma das mais flagrantes violações a esses direitos fundamentais do homem, o direito ao trabalho decente e ao acesso à jurisdição.

\subsection{Transação e renúncia no Direito do Trabalho}

Transação e renúncia são institutos que, em confronto com a teleologia da ordem jurídica trabalhista, devem ser aplicados com evidentes ressalvas na esfera das relações de trabalho: por um lado, é manifesto que a compatibilidade de tais institutos com o Direito do Trabalho e com as normas protetivas que dele se irradiam é severamente limitada pelos seus princípios fundamentais; por outro lado, de forma pragmática, não se deve limitar a proteção em tese - e a efetividade dessas normas protetivas - ao momento da execução do contrato individual de trabalho, mas estender tal proteção - e tal efetividade - ao encerramento da relação de emprego, com a instrumentalidade do processo do trabalho e a facilitação do acesso do ex-empregado à jurisdição trabalhista (art. $5^{\circ}$, XXXV, da Constituição) - o que transcende a preocupação singela com a simples pacificação formal do conflito e requer o exame da aptidão dos instrumentos processuais trabalhistas para garantir a credibilidade daquelas normas e o acesso efetivo à ordem jurídica justa - à justiça social, em última análise (ASSIS, 2012, p. 1015).

A adequada compreensão do alcance da transação nas relações de trabalho demanda que o exame conceitual do instituto seja realizado em conjunto com a figura da renúncia. Por um lado, a renúncia constitui negócio jurídico unilateral por meio do qual o renunciante abdica de um direito sem qualquer contrapartida pelo renunciatário. Em virtude dessa índole abdicativa, a legislação exige que tais atos sejam interpretados restritivamente (art. 104 do Código Civil), o que evita a extensão do objeto da renúncia para além daquilo a que efetivamente se renuncia. Por outro lado, a transação, como negócio jurídico bilateral, possui natureza contratual, e em sede de direitos patrimoniais privados e disponíveis, podem os interessados, mediante concessões recíprocas, prevenir ou finalizar um litígio (arts. 840/841 do Código Civil).

O instituto não se coaduna com a mera transmissão de direitos: apenas com a declaração ou o reconhecimento destes. Assim, por meio da transação, promove-se a segurança em relações jurídicas abaladas por conflitos de interesses qualificados pela res dubia. No Digesto, a res dubia já era referida quando do tratamento da transação: Qui transigit quasi de re dubia et lite incerta neque finita transigit qui vero paciscitur, donationis causa rem certam et indubitatam liberalitate remittit. Em outras palavras, se não houvesse dúvida acerca da disponibilidade e da titularidade de certos direitos, estes até poderiam ser objeto de renúncia, mas não de transação. $O$ tema, como se vê, tem relação com a própria interpretação do negócio jurídico. 
Não se harmonizam, portanto, com a transação as chamadas "quitações gerais", sem menção específica aos direitos e interesses a que se dirijam. O Código Civil, ao tratar da quitação, no seu art. 320, dispõe que o respectivo instrumento "[...] designará o valor e a espécie da dívida quitada, o nome do devedor, ou quem por este pagou, o tempo e o lugar do pagamento, com a assinatura do credor, ou do seu representante." (BRASIL, 2002). Desse modo, a exemplo da renúncia e dos negócios jurídicos benéficos, a extensão do objeto transacionado há de ser sempre aferida por interpretação restritiva (art. 843 do Código Civil).

No âmbito do Direito do Trabalho, ambos os institutos sofrem mitigações em seus efeitos, como corolário da incidência dos princípios da imperatividade das normas protetivas e da indisponibilidade, em termos gerais, dos direitos trabalhistas. Esses princípios se destacam na teleologia de vários dispositivos da Consolidação das Leis do Trabalho. Por exemplo, o art. $9^{\circ}$ da Consolidação das Leis do Trabalho dispõe que são "[...] nulos de pleno direito os atos praticados com o objetivo de desvirtuar, impedir ou fraudar a aplicação dos preceitos contidos" na Consolidação. Na mesma linha, o art. 444 da Consolidação das Leis do Trabalho prescreve que as relações contratuais de trabalho podem ser objeto de livre estipulação das partes interessadas em tudo quanto não contravenha às disposições de proteção ao trabalho, às convenções e acordos coletivos que lhes sejam aplicáveis e às decisões das autoridades competentes. Já o art. 468 da Consolidação das Leis do Trabalho condiciona a alteração das condições contratuais a dois requisitos que devem coexistir nos casos concretos, sob pena de nulidade: o mútuo consentimento e, a par deste, a inexistência de prejuízos diretos ou indiretos ao empregado, em virtude da alteração.

É fácil perceber que tal regramento mitiga a autonomia da vontade do empregado em face do desequilíbrio de poderes inerente à relação de emprego, estruturalmente assimétrica em termos de poder. Desse modo, busca-se impedir o despojamento, mesmo que consentido, das vantagens e das proteções asseguradas ao trabalhador pela ordem jurídica e pelo contrato. Assim, ao longo do vínculo empregatício, e mesmo após o término deste, não pode haver, como regra, nem renúncia nem transação prejudicial a direitos do empregado ou ex-empregado.

Os direitos trabalhistas podem ser classificados conforme o grau de sua indisponibilidade. Assim, há direitos tutelados por normas de interesse público e de indisponibilidade absoluta, o que afasta a possibilidade de sua relativização no contexto do contrato individual de trabalho, quer por transação, quer por renúncia; e há direitos que, não obstante a indisponibilidade de seu objeto, e apesar de também excluírem a possibilidade de renúncia pura e simples, admitem a transação quanto a alguns de seus aspectos, desde que não haja prejuízos ao empregado.

Há uma série de outras normas cogentes cujas determinações não podem ser afastadas pela vontade dos participantes da relação de emprego, de modo que os direitos tutelados por tais mandamentos permanecem imunes à renúncia ou à transação. É o caso, por exemplo, das normas que tratam de direitos fundamentais, como a inviolabilidade da intimidade, da vida privada, da honra e da imagem da pessoa, dos direitos da personalidade, que, por definição, são intransmissíveis e irrenunciáveis, e das disposições garantidoras da higidez do meio ambiente do trabalho, que buscam a redução dos riscos inerentes à atividade profissional. Assim, antes de celebrado o contrato indivi- 
dual de trabalho, durante o seu curso e mesmo após a extinção da relação de trabalho, a regra, com as ressalvas supracitadas, é a da indisponibilidade dos direitos.

$\mathrm{Na}$ prática, contudo, o empregado tende a questionar eventuais irregularidades em sua relação com o empregador apenas após o término do contrato individual do trabalho. É fato notório que a Justiça do Trabalho é uma Justiça de ex-empregados. Nesse contexto, apesar de todo o ideário protetivo enunciado, a vulnerabilidade econômica da maioria dos trabalhadores tende a oportunizar não apenas renúncias, mas também transações falsas, sem qualquer traço de res dubia, que não podem ser validadas pelo Poder Judiciário, sobretudo quando têm o escopo de trazer segurança ao ex-empregador, privando o ex-empregado do acesso à jurisdição trabalhista.

\subsection{Assimetria estrutural de poder entre os sujeitos da relação de emprego}

A ideia de proteção do trabalho e do trabalhador, com o seu desdobramento no princípio da irrenunciabilidade, constitui, como exposto, o núcleo axiológico do Direito do Trabalho, advinda da percepção de que o trabalhador se coloca sempre em uma posição desfavorável, em relação ao empresário, no âmbito do mercado de trabalho, pois as especificidades intrínsecas ao mercado geram verdadeira opressão ao trabalhador antes mesmo que entre eles se estabeleça, como empregado e empregador, o contrato individual e a própria relação de trabalho.

Essa posição desfavorável dos trabalhadores no mercado de trabalho é estrutural e decorre, entre outros, dos seguintes fatores:

a) embora seja, normalmente, tratada como mercadoria, a força de trabalho possui determinadas especificidades que não permitem a sua integração ao mercado como verdadeira mercadoria, como a impossibilidade de se limitar a sua oferta - vale lembrar o princípio fundamental da Declaração Referente aos Fins e Objetivos da Organização Internacional do Trabalho (Declaração de Filadélfia), de que o trabalho não é uma mercadoria;

b) a força de trabalho tornou-se completamente dependente de meios de subsistência oferecidos pelo mercado, que somente podem ser adquiridos se a força de trabalho for vendida, de forma que o trabalhador não pode aguardar uma oportunidade mais favorável para oferecer seu produto ao mercado, razão pela qual a força de trabalho é estruturalmente compelida a abdicar de quaisquer opções estratégicas ou das lógicas do mercado para se submeter às condições impostas pela demanda no momento e aceitar as condições de trabalho oferecidas;

c) as necessidades da oferta são muito mais rígidas do que as da demanda, pois, enquanto os trabalhadores dependem, para a manutenção de uma qualidade mínima de vida, determinada material e culturalmente, da constante venda de sua força de trabalho, os empresários podem manter a produção em níveis regulares mesmo com a queda da utilização da mão de obra, por meio do incremento da tecnologia; 
d) o capital possui maior liquidez do que a força de trabalho, pois o empresário pode, ao final de um ciclo, renovar sua unidade produtiva, adequando-a às novas tecnologias, ou mesmo alterar ou expandir a sua área de atuação, ao passo que o trabalhador, ao contrário, somente pode variar a qualidade de sua oferta em grau bastante reduzido e de forma condicionada a alguma espécie de apoio externo, como educação e treinamento.

Não podendo o trabalhador optar por não participar do mercado de trabalho, a ausência das leis sociais imperativas no âmbito desse mercado conduziria a uma exploração cada vez mais violenta, tornando insustentável a própria mecânica do mercado e, em consequência, o próprio modelo de produção. ${ }^{10}$

A assimetria inerente à relação de emprego, portanto, sendo estrutural, não se limita às relações individuais de trabalho, estendendo-se às relações coletivas. Não é por acaso, portanto, como asseverou, no caso concreto, paradigma para a repercussão geral, o Juiz de primeira instância, que o plano de demissão incentivada do BESC foi objeto de acordo coletivo de trabalho formalizado "[...] mesmo contra a orientação da entidade de classe."

\subsection{A experiência empírica - o precedente do ROAA 111500-48.2002.5.12.0000}

O plano de demissão incentivada do BESC foi objeto de anterior ação anulatória e ação cautelar, ajuizadas pelo Ministério Público do Trabalho, precisamente em virtude da cláusula que estipulava a renúncia genérica a direitos como condição para a adesão ao plano - ação que levou, no âmbito do Tribunal Superior do Trabalho, à instauração de Incidente de Uniformização de Jurisprudência, que concluiu pela invalidade de cláusula de acordo coletivo de trabalho que estabelece a quitação plena do contrato individual de trabalho em razão da adesão do empregado a plano de demissão incentivada.

Nas ações em questão, o Ministério Público do Trabalho, no exercício das competências previstas no art. 83, IV, da Lei Complementar n. 75/1993, apontava exatamente a violação dos direitos e das liberdades individuais dos empregados do BESC a partir do acordo coletivo de trabalho, cuja declaração de nulidade foi o objeto do pedido.

No caso, o Tribunal Superior do Trabalho ponderou o fato que aquela Corte vinha, em regra, anulando comandos de convenções ou acordos coletivos de trabalho que infirmem a tutela mínima outorgada aos empregados por norma heterônoma, como, por exemplo, aqueles que mitigam o intervalo intrajornada legal - o Tribunal Superior do Trabalho, nesses precedentes, havia firmado o entendimento de que "[...] o empregado merece proteção, inclusive, contra a sua própria necessidade ou ganância, quando levado a anuir com preceitos coletivos que lhe subtraem direitos básicos." Fixada tal premissa, passou à análise do caso do BESC.

Constatou, inicialmente, que o Banco do Estado de Santa Catarina S/A, após ser federalizado, "[...] encetou profunda reestruturação organizacional, voltada, sobretudo, ao corte de custos

\footnotetext{
$\overline{10}$ Sobre essa assimetria estrutural, ver Offe (1989).
} 
operacionais, que viabilizaria futura privatização." A partir de tal projeto de "saneamento" econômico, a redução do respectivo quadro funcional e do correspondente passivo trabalhista ganharam "[...] cuidado especial por parte dos dirigentes da instituição."

O programa de demissão incentivada revelava-se, assim, como "[...] o mecanismo adequado para que estes dois objetivos fossem atingidos, pois daria ensejo à dispensa da mão-de-obra excedente e à obtenção da quitação dos débitos trabalhistas relativos aos empregados dispensados."

Quanto ao propósito de realizar dispensas em massa, porém, havia um entrave: "[...] o regulamento da empresa contemplava os empregados do BESC com a estabilidade no emprego, o que, obviamente, vedava a extinção dos contratos de trabalho, ainda que bilateral."

Portanto, para tornar factível a dispensa de pessoal, fazia-se necessária a celebração de instrumento coletivo que firmasse a disponibilidade do direito à estabilidade, irrenunciável por meio de simples acordo individual.

Isso significa dizer que o BESC, para imprimir validade jurídica ao seu programa de demissão incentivada, devia, de fato, estampar em ajuste coletivo a possibilidade de o empregado dispor da estabilidade.

Nesse ponto, a celebração do acordo coletivo de trabalho afigurou-se escorreita, prevendo que o empregado do BESC, caso resolvesse aderir ao programa, abriria mão de um direito - a estabilidade - para auferir, em troca, significativa vantagem econômica - a indenização.

No entanto, a gestão da instituição, dentro do projeto mais amplo de seu saneamento econômico, almejava conseguir mais do que a redução do quadro de pessoal: queria eliminar o passivo trabalhista quanto aos empregados que se desligassem da empresa em virtude da adesão ao citado programa de dispensa incentivada, mediante a quitação geral dos respectivos contratos de trabalho.

Sucede que a notória diretriz da SDI-I do Tribunal Superior do Trabalho, consolidada na Orientação Jurisprudencial n. 270, constituía evidente empecilho a tal desiderato.

O "detalhe" técnico não passou despercebido ao corpo jurídico do BESC, pois este, em experiência anterior de implantação de PDV, terminou por figurar em dois precedentes invocados para a cristalização da jurisprudência sobre a matéria (E-RR 653383/2002, DJ 24/05/2002; E-RR 475180/1998, DJ 05/04/2002).

Daí se compreende a estratégia do BESC, que tratou de passar a incluir, no acordo coletivo de trabalho, também dispositivos que obrigam o empregado desejoso em participar do programa de demissão incentivada a conferir quitação plena, geral e irrestrita do contrato de trabalho, "transacionando" eventuais pendências.

Igualmente, as propaladas normas coletivas asseguraram aos empregados a voluntariedade da adesão, a assistência sindical para o ato e a possibilidade de desistência da adesão feita.

Naturalmente, o estratagema do Banco visou a afastar todos os virtuais óbices que, presumivelmente, seriam levantados contra o efeito atribuído à adesão ao PDV, de quitação plena dos contratos de trabalho rescindidos.

Daí que as cláusulas coletivas em questão atentam contra normas elementares do Direito do Trabalho. 
Nesse sentido:

Como se sabe, a transação é ato jurídico bilateral e sinalagmático, pelo qual as partes fazem concessões recíprocas acerca da "res dubia" para evitar um litígio ou, se for o caso, para por fim a um litígio já iniciado. Inequivocamente, não repugna ao Direito do Trabalho a transação consumada na pendência de processo judicial em que se supõe litigiosa a pretensão jurídica ali deduzida. Bem ao revés, a lei estimula a conciliação com efeito de transação em diversos preceitos (CLT, arts. 764, $\$ 3^{\circ}$, 846 e 850).

Compreende-se tal estímulo como mecanismo de restabelecimento da paz social violada. Ademais, há troca de um direito litigioso ou duvidoso por um benefício concreto e certo. Em síntese, se é fato que o empregado transator sacrifica, no todo ou em parte, um direito ou uma vantagem, não menos exato que, em contrapartida, obtém alguma vantagem ou benefício. Daí porque entendo que na pendência de processo judicial as partes são inteiramente livres na autocomposição da lide trabalhista, em princípio.

Penso, todavia, que em se tratando de transação extrajudicial para prevenir litígio, impõe-se encarar com naturais reservas a validade da avença no plano do Direito do Trabalho.

Em primeiro lugar, porque se se permitir que todos os direitos trabalhistas sejam passíveis de negociação individual com o empregador, certamente voltaríamos à estaca zero do Direito do Trabalho: nenhum empregado deixaria de "transigir" em maior ou menor medida e, assim, desapareceriam as razões econômicas, sociais e ideológicas que ditaram o surgimento do Direito do Trabalho como ramo da Ciência Jurídica de cunho eminentemente protecionista do trabalhador hipossuficiente. Em segundo lugar, porque cumpre considerar que no Direito do Trabalho a tônica é precisamente o esvaziamento do princípio da autonomia da vontade, tão caro aos civilistas, como se depreende de vários preceitos da CLT, mormente os arts. 444,468 e $9^{\circ}$. Ora, tudo isso conflita abertamente com o poder de disposição de direitos subjetivos mediante transação.

Em terceiro lugar, porque a idéia de transação extrajudicial envolvendo quitação total e indiscriminada de parcelas do contrato de emprego esbarra na norma do

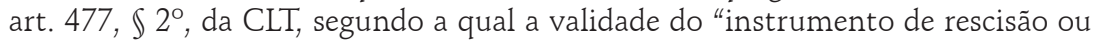
recibo de quitação, qualquer que seja a causa ou forma de dissolução do contrato, deve ter especificada a natureza de cada parcela paga ao empregado e discriminado o seu valor, sendo válida a quitação, apenas, relativamente às mesmas parcelas". Em quarto lugar, porque não cabe cogitar de transação válida nem sequer "res dubia", tal como se dá na hipótese vertente.

Com efeito, a quantia que o empregador paga ao empregado em virtude de este aderir a plano de desligamento voluntário constitui uma indenização especial destinada a fazer face à perda do emprego.

Na hipótese dos autos, portanto, a acenada vantagem pecuniária não traduz, pela sua natureza, resgate de dívida trabalhista controvertida, vale dizer, não é contrapartida em relação a eventuais direitos trabalhistas insatisfeitos.

Entendo que, juridicamente, não há sequer transação quando o empregado sacrifica quaisquer possíveis direitos exclusivamente por conta da indenização do PDV. Há aí, sim, renúncia, incompatível com o Direito do Trabalho.

Não me convence a objeção de que o empregado, ao aderir ao programa de dispensa incentivada do BESC, exerceria plenamente a sua liberdade individual, porquanto não seria forçado a participar do plano, bem como teria o acompanhamento e a orientação do sindicato quanto aos efeitos deste.

Afigura-se-me irrelevante tal aspecto no âmbito do Direito do Trabalho, cuja característica, insisto, é o esvaziamento do princípio da autonomia da vontade, precisamente porque o empregado trava relação desigual com o empregador, encontrando-se premido em suas decisões pelas necessidades econômicas de sobrevivência.

Noto que o caso vertente bem ilustra essa posição de desvantagem do trabalhador. A aventada liberdade de escolha não passa de jogo de retórica, se atentarmos para a realidade social sob enfoque. 
Com efeito, as opções que se colocam à frente do empregado do BESC são ou receber a indenização ofertada, verba certa e significativa, ou ficar na empresa, assombrado com o futuro, sem saber qual a sorte que lhe reservará o sucessor da empresa. Não é de se estranhar, assim, o grande interesse dos trabalhadores em aderirem ao plano, apesar da concessão abrangente que tal ato implica.

Chamo a atenção, por isso, para o caráter emblemático que o caso ostenta. Um Banco federalizado, prestes a ser privatizado, procura viabilizar política econômica por meio de normas coletivas que ocultam evidente afronta à ordem jurídica trabalhista, valendo-se do natural estado de apreensão de seus empregados.

Resta examinar se, em face do reconhecimento constitucional dos acordos coletivos de trabalho (art. $7^{\circ}$, inc. XXVI), seria lícito ao Sindicato da categoria profissional celebrar a avença nos termos em que a firmou.

A meu juízo, não.

O poder de disposição do sindicato em relação aos direitos individuais dos representados, de conformidade com a Constituição Federal, concerne estritamente a salário e jornada. Se lhe fosse dado ir adiante, não teria sido encetada, recentemente, uma fracassada tentativa de mudança da CLT exatamente para emprestar prevalência ao negociado entre sindicatos e patrões, em confronto com a lei, o que, na prática, apenas abriria caminho para a redução de importantes direitos trabalhistas, tal como se dá no caso sob exame.

Não é lícito, portanto, ao sindicato negociar a quitação ampla e irrestrita de prestações genéricas do contrato de trabalho dos seus representados.

Sem mais, inconcebível admitir que o sindicato pudesse firmar uma avença que, por seu conteúdo, ao próprio empregado representado não é assegurada pela legislação trabalhista, de conformidade com a Orientação Jurisprudencial de $\mathrm{n}^{\circ} 270$, da SDI - I do TST.

Em realidade, na espécie, o Sindicato da categoria profissional e o Recorrente buscam conferir uma fachada de licitude a um ajuste sobre direitos individuais indisponíveis, ajuste este que, em última análise, importa abrir caminho para que se frustre e fraude a legislação trabalhista tutelar, o que, também por isso, inquina de invalidade as cláusulas em apreço, em face do que estatui o art. $9^{\circ}$ da CLT.

\section{À guisa de conclusão}

A tese esposada pelo Supremo Tribunal Federal no julgamento do Recurso Extraordinário 590415/SC, que afirmou, com repercussão geral, em sentido contrário aos precedentes do Tribunal Superior do Trabalho, a tese de validade da renúncia genérica a direitos emergentes da relação de emprego mediante adesão do empregado a plano de demissão voluntária previamente aprovado por acordo coletivo de trabalho, é um precedente flexibilizador do princípio da irrenunciabilidade, fundamental ao Direito do Trabalho.

Fundada, embora, em standards teoréticos de proteção logicamente razoáveis, a decisão do Supremo Tribunal Federal, flexibilizando um dos principais - se não o principal - cânones do Direito do Trabalho (o princípio da irrenunciabilidade), vai ao encontro, nos seus fundamentos, de um movimento de flexibilização do Direito do Trabalho, de prevalência do negociado coletivamente sobre o legislado, que, desconhecendo a experiência histórica da Justiça do Trabalho, relativiza a assimetria de poder entre os sujeitos da relação de emprego no âmbito do direito fundamental ao trabalho, ignorando importantes questões para o futuro do trabalho no País, como: 
a) a assimetria de poder entre os sujeitos da relação de emprego no âmbito da relação de trabalho, sendo estrutural, não é neutralizada pela negociação coletiva, e a prévia autorização, pela via da negociação coletiva, para renúncias que se efetivam no plano individual não obstam o fundamento e o escopo da limitação da autonomia da vontade do empregado em razão de tal assimetria;

b) a efetividade da negociação coletiva, no Brasil, deve ser problematizada à luz dos standards delineados pela Organização Internacional do Trabalho em termos de liberdade sindical e de negociação coletiva, destacando-se, em qualquer hipótese, que a negociação coletiva não é um fim em si mesmo, possuindo um caráter meramente instrumental no sistema de princípios e direitos fundamentais no trabalho da Organização Internacional do Trabalho;

c) os princípios básicos que informam os institutos da transação e da renúncia devem, no âmbito das relações de trabalho, ser interpretados e aplicados em conformidade com a teleologia da ordem jurídica trabalhista e, sobretudo, com os princípios fundamentais da irrenunciabilidade e da garantia de acesso à jurisdição trabalhista;

d) não há eficazes prevenção e pacificação de conflitos sem justiça social.

Nesse contexto, aquela máxima apontada na Exposição de Motivos da CLT, de 1943, da prevalência de uma ordem trabalhista fundada na precedência das normas de tutela sobre os contratos (item 28 da Exposição), ou seja, da precedência do legislado sobre o negociado, continua extremamente atual: a ratio legis do sistema normativo mínimo, infenso à renúncia e à transação, necessário à manutenção de relações de trabalho minimamente decentes no Brasil, continua presente - deve haver, no Direito do Trabalho, um núcleo duro irrenunciável em prol do homem, infenso, portanto, à renúncia e à transação. Núcleo duro que não se esgota nos direitos reconhecidos constitucionalmente, mas que também abrange, além de direitos relacionados à saúde e à segurança do trabalhador, direitos econômicos, sempre tendo presente a limitação da autonomia da vontade do empregado em razão da assimetria de poder entre os sujeitos da relação de emprego.

\section{REFERÊNCIAS}

ASSIS, Luís. Transação. In: SCHWARZ, Rodrigo García. (Org.). Dicionário de direito do trabalho, de direito processual do trabalho e de direito previdenciário aplicado ao direito do trabalho. São Paulo: LTr, 2012.

BAYLOS, Antonio Pedro. Contrato de trabajo e irrenunciabilidad de derechos. In: BAYLOS, Antonio Pedro; THOMÉ, Candy Florencio; SCHWARZ, Rodrigo García (Org.). Diccionario internacional de derecho del trabajo y de la seguridad social. Valencia: Tirant Lo Blanch, 2014.

BRASIL. Lei n. 10.406, de 10 de janeiro de 2002. Institui o Código Civil. Diário Oficial da União, Brasília, DF, 10 jan. 2002. 
BRASIL. Supremo Tribunal Federal. Recurso Extraordinário 590415/SC, de 24 de setembro de 2012. Relator Min. Joaquim Barbosa. JusBrasil, 04 out. 2012.

CUEVA, Mario de la. El nuevo derecho mexicano del trabajo. México: Porrúa, 1972.

DEAN, Hartley. The juridification of welfare: strategies of discipline and resistance. In: KJØNSTAD, A.; WILSON, J. V. (Org.). Law, power and poverty. Bergen: CROP, 1997.

FERRAJOLI, Luigi et al. Los fundamentos de los derechos fundamentales. Madrid: Trotta, 2001.

FREITAS JÚNIOR, Antonio Rodrigues de. Poder directivo y eficacia horizontal de los derechos humanos. In: BAYLOS, Antonio Pedro; THOMÉ, Candy Florencio; SCHWARZ, Rodrigo García (Org.). Diccionario internacional de derecho del trabajo y de la seguridad social. Valencia: Tirant Lo Blanch, 2014.

MARSHALL, Thomas; BOTTOMORE, Tom. Ciudadanía y clase social. Madrid: Alianza, 1998.

MARTÍNEZ, Gregorio Peces-Barba. Curso de derechos fundamentales: teoría general. Madrid: Universidad Carlos III, 1995.

MEYER, Nadège. L'ordre public em droit du travail. Paris: LGDJ, 2006.

OFFE, Claus. Capitalismo desorganizado: transformações contemporâneas do trabalho e da política. São Paulo: Brasiliense, 1989.

RODRÍGUEZ, Américo Plá. Los principios del derecho del trabajo. 2. ed. Buenos Aires: De Palma, 1990.

WILSON, John Veit. Law, power and poverty. Bergen: CROP, 1997.

XAVIER, Bernardo da Gama Lobo. Curso de direito do trabalho. Coimbra: Verbo, 1993

Data da Submissão: 01 de dezembro de 2015

Aceito em: 12 de abril de 2016 
